\title{
A reflective study into children's cognition when making computer games
}

\section{By Yasemin Allsop}

Yasemin Allsop worked as an ICT Coordinator in primary schools in London for almost 10 years. She is currently employed as Senior Lecturer in Primary Computing and ICT at Manchester Metropolitan University. She has MA ICT in Education from the London Knowledge Lab, University of London. She is also an MPhil/PhD student at Goldsmiths, University of London, focusing on children's thinking and learning when designing digital games. She is the editor of an online magazine called ICT in Practice where educators from around the world share their experiences of using technology in education.

Flat $1^{\text {st }}$ Floor, 83 Dollis Road

London

N3 1RD

Email: yallsop@msn.com

\section{What is already known about this topic}

- Game making activities help children to develop problem-solving skills

- Game design supports learners in developing subject knowledge in literacy and mathematics.

- Children can develop transferrable skills through computer game design such as collaborative work and communication.

\section{What this paper adds}

- $\quad$ This paper explores the process behind learning when children design their own computer games and how this relates to thinking, rather than looking at the end product, or the impact on learning in a specific subject.

- $\quad$ This study provides recent data from a primary classroom in the UK using participant observations, informal conversations, in-depth interviews, learning journals and video interviews.

- This paper looks at the relationship between thinking-learning and metacognition when children are making their own computer games

\section{Implications for practice and/or policy}

- $\quad$ Understanding how children learn and think will be a good starting point for educators to design learning experiences for their students

- $\quad$ Knowing the process of learning and thinking when children are making their own computer games is useful when exploring the educational value of this medium

- $\quad$ Studying how new technologies impact on children's thinking and learning is very helpful, when embedding these technologies into teaching and learning in the classroom

\begin{abstract}
In this paper, children's mental activities when making digital games are explored. Where previous studies mainly focused on children's learning, this study aimed to unfold the children's thinking process for learning when making computer games. As part of an on-going larger scale study, which adopts an ethnographic approach, this research reports on how children think when making their own computer games using their 'Thinking Maps' and video recordings of group discussions. A model for Thinking for Learning, 'think-to-learn-to-think' is discussed and children's activities used to define the stages of this cycle. The study of children's Pre-during-after project 'Thinking Maps' and explanations during group discussions suggests that their thinking sequences were altered during and after their game design activities. The children presented their 'thinking process' when designing computer games as a continual circular cycle and described their mind as a virtual lab to plan and visualize solutions before testing them on screen, using the 'Alice' game design program.
\end{abstract}

\section{Introduction}

Looking at the rapid technological developments in recent years, it won't be wrong to suggest that computer and video games are currently the most discussed and written topic. In the first instance the main motive for this is seen as the number of hours children are spending in front of screens playing their favourite games, nonetheless the socio-emotional impacts of games on children's lives cannot be ignored. What drew more attention was, when educators started to see the power of this new medium and explore ways to use computer games to support learning within schools. Parallel to learning with 
playing computer games, there is also an increasing interest in children creating their own games and its educational value. This might be flourished by the recent influences of constructivist theories on technology-supported learning, where learners actively build knowledge through experiment and discovery. The ease of having access to a vast range of game design programmes online and the ability to create digital games without any knowledge of technical skills has also motivated this interest. Previous studies into children's game making practices focused on the impact on specific learning areas such as; literacy skills (Good and Robertson, 2004, 2006), story telling and writing skills (Dyer, 2008), skills in the areas of mathematics, science, art and computer literacy (Yatim and Masuch, 2007); some studied as part of game literacy, teaching students to learn to be critically, creatively and culturally accomplished individuals (Buckingham and Burn, 2007). There were also some studies looking at children developing their thinking skills through game design activities. Papert (1998) used programming as a way to promote learning general thinking skills. He described programming as a construction tool for personal expression and knowledge construction, which empowers students to explore the psychological and cultural aspects of learning. Jonassen (1996), defined computers as cognitive tools, when used with constructivist learning environments, it activates critical thinking and learning. Jonassen (1999) describes technology as 'the designs and environments that engage learners'. He also talks about how learners learn the most when they become the designer of the learning materials, rather than just learn from it. Kafai $(1995,1996)$ studied children's game design activities and suggested that game design is a context for children to practice and develop transferable skills such as planning, mathematical thinking and problem solving. Dyer (2008), focused on a number of games making projects for primary school children that aimed to develop, students' storytelling and writing skills based on the curriculum. As a result Dyer explains that creating digital games; motivates learners to achieve, increase self-esteem, provides opportunities for collaborative learning, develops problem solving, develops students ability to observe, question, hypothesize, test and facilitate metacognitive reflection.

There is no doubt that technological advances are changing not only the way we communicate but also the way we think and learn both as individuals and socially. What is remarkable is the way our brain responds to these technological innovations. In an attempt to adapt to this new environment and cope with constant simulations, our brain is developing new capabilities and strategies. In other words, redesigning the process of thinking which shapes our learning. This innovation is not only affecting the adults of today but also the children of the digital age. Children's interactions with the new technologies, either through playing games or designing their own games is gradually transforming their own internalized thinking along with how they conceptualise learning in a social context. There has been a shift in the anatomy of thinking and learning from a ready - static to an interactive-dynamic experience. The learners are no longer passive learners waiting to be taught; they are the head engineer of their mind lab where they design and control their thinking process sometimes alone, sometimes in partnership with the facilitator-teacher, parent, friend or computer, which leads to learning at anytime, anywhere. However defining the context of how this change impacts on the thinking pattern of a child is still a vague area. The main difficulty is how we can observe the child's mind and take an image of their mental activities whilst making games, as thinking is not always visible. Their game designs could give us information on whether they were able to use the software to create a game, however it doesn't explain the steps in the cognitive process such as; how they solved the problem, the strategies they used, the steps they followed and so forth. This study aims to explore this further.

\section{Defining the Focus}

It is appropriate to suggest that digital game making can be seen as a learning space to develop children's thinking, as it engages learners with constant problem-solving activities, however there isn't much information on whether this affects the foundations of the way the child thinks. Formulating this as a question, 'Do digital game design activities impact on children's thinking patterns for learning and how?' This is a very difficult question to answer, nevertheless a very important one as it is directly linked to the way the child learns. One-way of finding an answer is to explore one's cognition, basically entering into the mind of a child. 'Cognition' as an umbrella term, includes all the mental activities that lead to gaining, storing, connecting and transferring of knowledge and skills. It can be seen as a brain's thinking function to design solutions for problems. Thus, if we are to understand children's thinking processes when designing their own games the interrelation between thinking, learning and metacognition needs to be explored, as they are all strands of one's cognition. The following section will explore this relationship, which I call 'think-to-learn-to-think, as it is not only interrelated, but also a continuous, overlapping process at times. 
Think-to-Learn-to-Think...

It is apparent that the thinking element of game design activities is becoming a focus, as there is a growing emphasis on teaching children critical thinking skills, so that they will become successful learners. Thus, defining what thinking is and how best to teach it with technology is still hazy. One of the biggest misconceptions in this area is, thinking as a function is mostly evaluated through specific learning outcomes, rather than studying the process of cognitive activities in one's mind. In a closer look thinking, as the main foundation of cognition can be seen as the process of making constant connections between what we know and what we understand of concepts to develop further meanings. The firm bond between thinking and learning extends this definition further. According to Perkins $(1992,2003)$ learning is a consequence of thinking and successful learning depends on making thinking visible. Thinking isn't only a mental process as it involves dialogue with 'self' but also with 'others'; likewise learning cannot be merely defined as the process of gaining knowledge. Learning and thinking are profoundly interrelated motions, overlapping at times.

Thinking is, indeed partly a mental process to learn, through the inward and outward effects of one's actions in the physical world which constitutes the skills of enquiry, creative thinking, reasoning, information processing and evaluation (National Curriculum, 2004). As to learning, it can also include developing the ability to think critically and to be analytical, to use information effectively, to make decisions, to think imaginatively, creatively and critically (Jessel, 2012). Noticeably, both notions include many similar skills. However having these skills doesn't alone guarantee that the student will learn. Learning is extensively derived on how well students can transfer and apply these skills to different learning contexts. Bransford et al. (2000, p.55) states that the transfer of the skills and knowledge is possible when learning involves more than simple memorization or applying a fixed set of procedures. Foremost, the student needs to understand the concepts and become expert in the skills, then know how and when to apply the skills to new situations. Although these steps look very straight forward, it is only viable when one develops the ability to understand and reflect their own thoughts, in other words metacognitive skills (Flawell, 1979; Fisher, 2005). Cross \& Paris (1988) defined metacognition as; the knowledge and control children have over their own thinking and learning activities. Students can improve their learning by being aware of their own thinking and regulating their learning activities. The heart of metacognition is to be able to think inwards and organize the mental activities in mind, by visualizing the steps through conversations with 'self'. This is a very important point as when a child is asked to 'think', it basically directs them to use their internal voice to talk with 'self'. Thus, it looks like being part of a cognitive process; metacognition is a high level thinking skill on its own. Sternberg (1998, p.17) states that metacognitive skills are driven by motivation which activates learning and thinking skills, then feeds back into the metacognitive skills, enabling one's level of expertise to increase. According to Sternberg these processes involve planning, evaluating and monitoring problem-solving activities and allocating cognitive resources appropriately is central to intelligence.

\section{Method}

The data was collected for a period of six months using participant observations, informal conversations, in-depth interviews, learning journals and video interviews for a wider scale research which had more extensive focus than here. However, for the purpose of this study children's before, during and after game design 'Thinking Maps' and video recordings of group discussions will be analyzed to gain an understanding of their mental activities when making their own digital games. A class of 30 children aged 10 / 11 were taught how to design digital games using 'Alice' which is a freeware object orientated 3D game design environment.

Thinking Maps. Before the game design sessions started the children were given a blank sheet of paper and asked to explain how they think when they learn in any subject. They were not given any specific layout, so that they could reflect their own thinking context and style freely rather than using a set framework. They were asked to keep their thinking map during game design activities with them so that if there was any alteration that they wanted to make they could annotate directly onto it. At the end of the project, the children were asked to draw another thinking map to show their thinking for the learning process during the game design activities.

Group discussions. There were 2 discussions held on separate occasions; one during the game design project and one at the end of the project. Each lasted for 40 minutes. The discussions were video recorded and focused on the children's view of the thinking process when making computer games in comparison to other activities in relation to learning. 
Studying the Children's Thinking Maps

Child A's Thinking Map

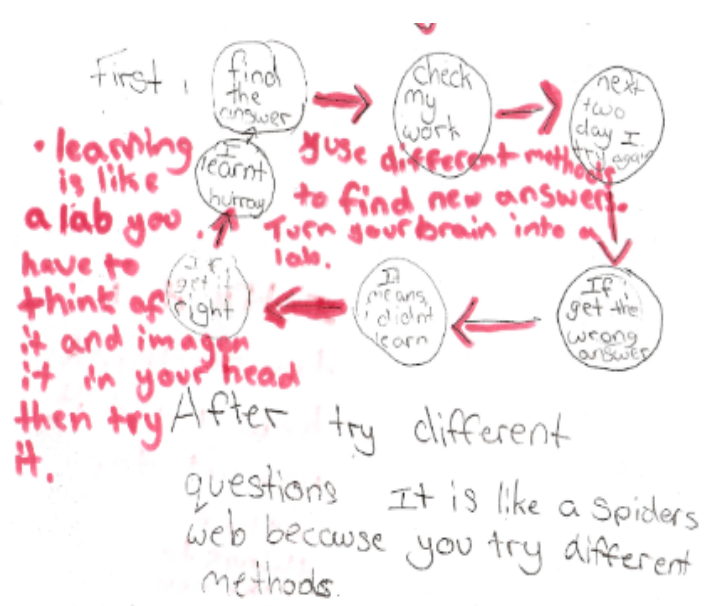

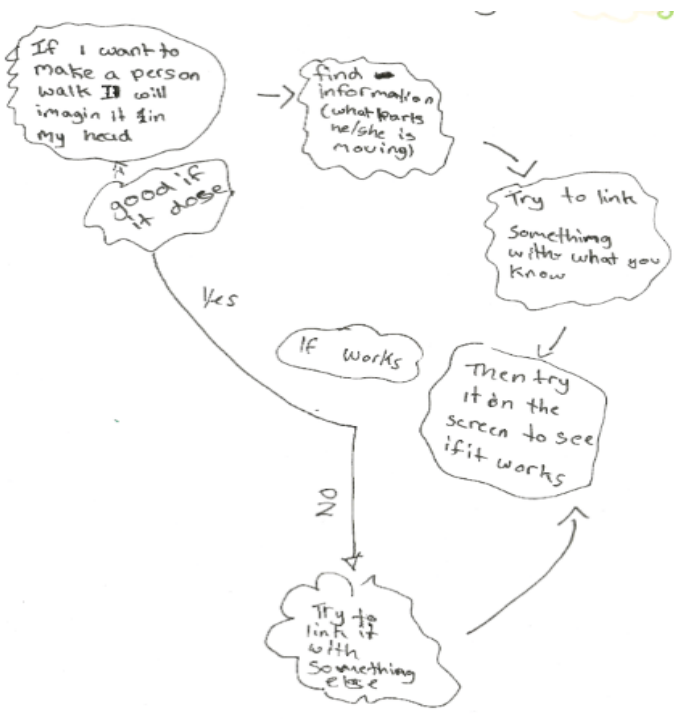

Figure 1: Child A's Pre-project Thinking Map Figure 2: Child A's After-project Thinking Map with annotations

In her Thinking Map before the game design activities (Figure 1), Child A drew out the process as a continual diagram and described it as a 'spiders web'. Her thinking started with an answer straightforward, then checking if her answer was right. It gets interesting, as she talks about remembering the concept again and being able to use it in couple of days time. She ends her map by suggesting that if she doesn't remember how to answer after couple of days she did not learn but if she does, she defines this as she learned. Underneath her diagram she also wrote the word 'concentrate' and 'think different things'. She annotated her map during game design and she had written "Learning is like a lab; you have to think of it and imagine it in your head then try it out. Use different methods to find answers. Turn your brain into a lab". Her thinking map after the game design (Figure 2) has a different layout but is still drawn as a continual process. She starts with imagining the task in her mind; "If I want to make a person walk, I will imagine it in my mind". She then looks for the information required to accomplish the task. She links what she has found to what she already knows. She tries out her design on screen to see if it works. If it doesn't she suggest linking different information.

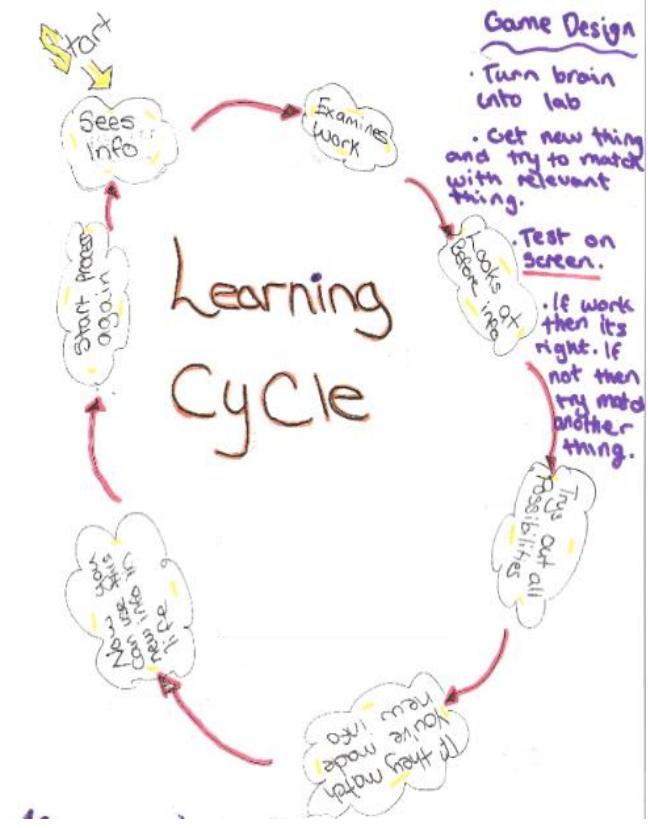

Figure 3: Child B's Pre-project Thinking Map

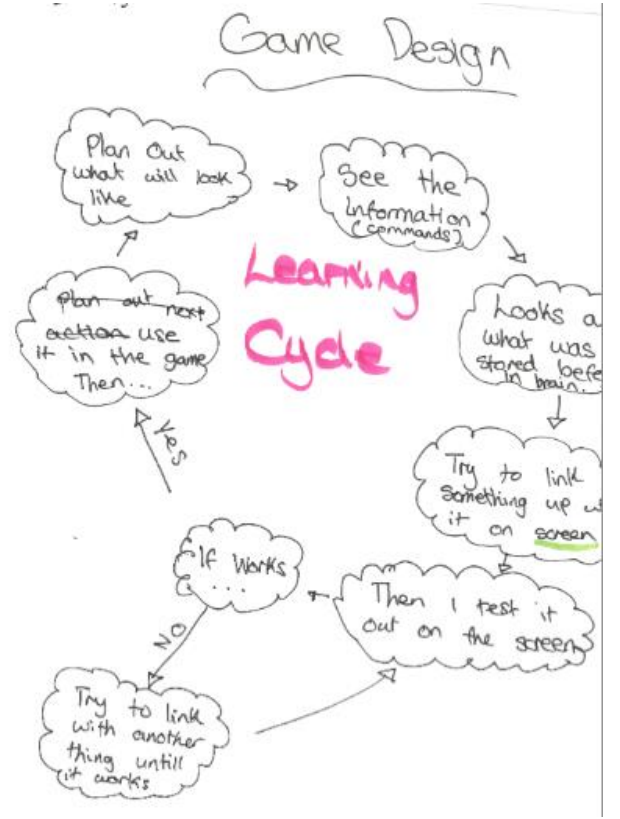

Figure 4: Child B's After-project Thinking Map with annotations

Child B's thinking map has a continual circular layout. She marked the 'Start' point clearly. Her 


\section{A study into children's cognition when making computer games}

starting point is receiving information. Examining the work, looking at the prior knowledge, trying out all the possibilities, if they work you gained new information, which you can use in life, followed this. Then she starts the process again. What is remarkable is that in her 'during game design thinking map'; she also mentioned turning her brain into a lab. She mentioned trying different ideas/methods (Engineering), testing on the screen and if it doesn't work try other things. Her thinking map after game design was also a circular continual cycle. She started the process by planning her game "what it would look like', then looking at the information on the game program such as commands (explore), then checking what she already knows and if she could link that with the something on screen. She then moves onto testing stage (Experiment), if it doesn't work, then she suggested linking another thing until it works. If it works then it can be used it in the game. When she was asked to explain this during group discussion her answer was "Lets say I used codes, for example I wanted to make the girl walking towards the car ok, I create the methods and the properties and function, maybe a variable, I don't know, I might need it, so together I create a line of codes, if this works, the girl moves where I want her to move, then I can use it when I make maybe a zombie to move'. What this actually tells us is, she uses codes to program the object to move to a target point. She experiments with codes to conceptualize the action 'move' using a trial and error method. She then stores this concept in her mind to use another time when in a similar situation. She constantly checks her design for errors and makes corrections to manipulate the object/s to create the desired action. This is a very complex activity and requires one's ability to analyze their internalized thoughts, visualize the effects of their thoughts on the actual design, then reflect on it by applying their thoughts onto the design itself using sets of codes.

\section{Child C's Thinking Map}

Child C's map (Figure 5), before the game design when compared to the two girls above is not in a circular cycle. He uses examples to explain his thinking rather than listing the steps. He places his

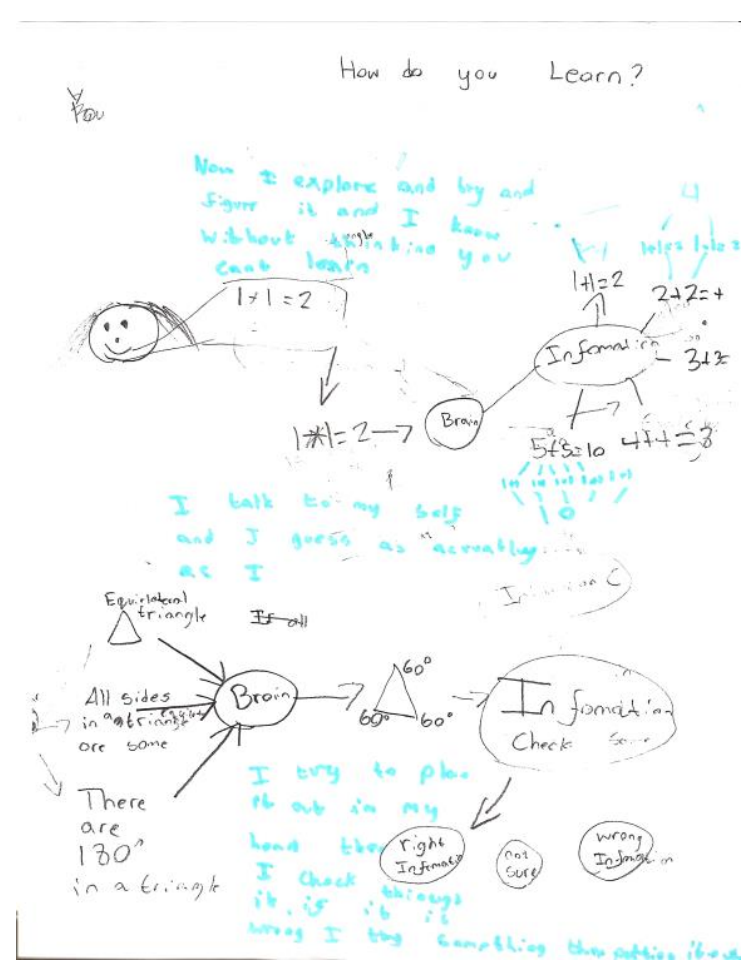
brain at the centre of problem solving and shows how different information related to a problem has been connected and checked, he classifies some information right, some as wrong, placing a not sure option in the middle. His alteration on the map during the game design has textual explanations. He starts with; "Now, I explore and try and figure it and I know without thinking you can't learn". His second sentence is; "I talk to myself and I guess as accurately as $I$ ". His final sentence says, "I try to plan it out in my head then I check things, if it is wrong I try something, then putting it right".

Notice, 'talking to self' and 'planning in the head' was first mentioned during game design activities. This doesn't mean he did not use these functions before, however it seems as though he is now aware of his own thinking and able to reflect upon his mental activities.

Figure 5: Child C's Pre-project Thinking Map with annotations

His after game design Thinking Map (Figure 6, has linked 4 boxes with text in them, although it is not circular. He starts with trying out what happens if he clicks on the buttons on Alice (Explore); then he uses the information he gained from trying out to plan what to do (Engineer); then he tries out his plan/s to create a final game (Experiment/ then Elicit). If he came across a problem, he tries stuff out until he gets it right (Error checking / Evaluate). His thinking sequence is clearly mapped out and his final step tells us that he is engaged with the activity because when he comes across a challenge/issue he doesn't give up, but tries out different possibilities until he finds the solution. 


\section{A study into children's cognition when making computer games}

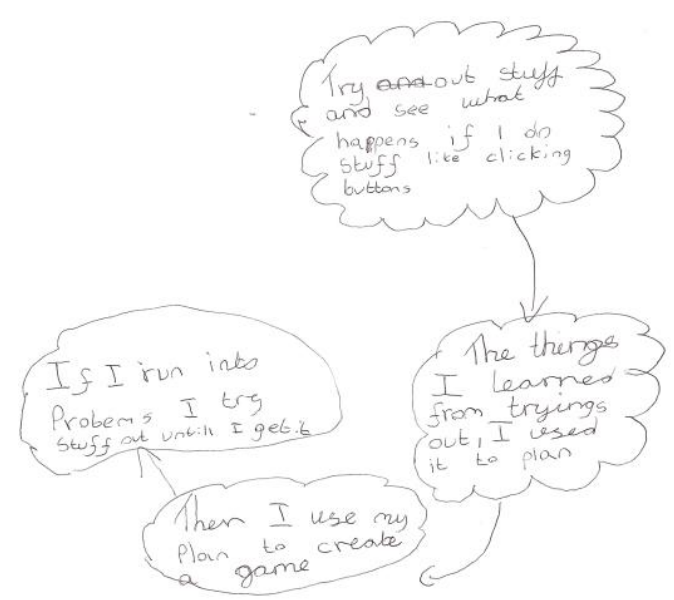

Figure 6: Child C's After-project Thinking Map

Child D's Thinking Map
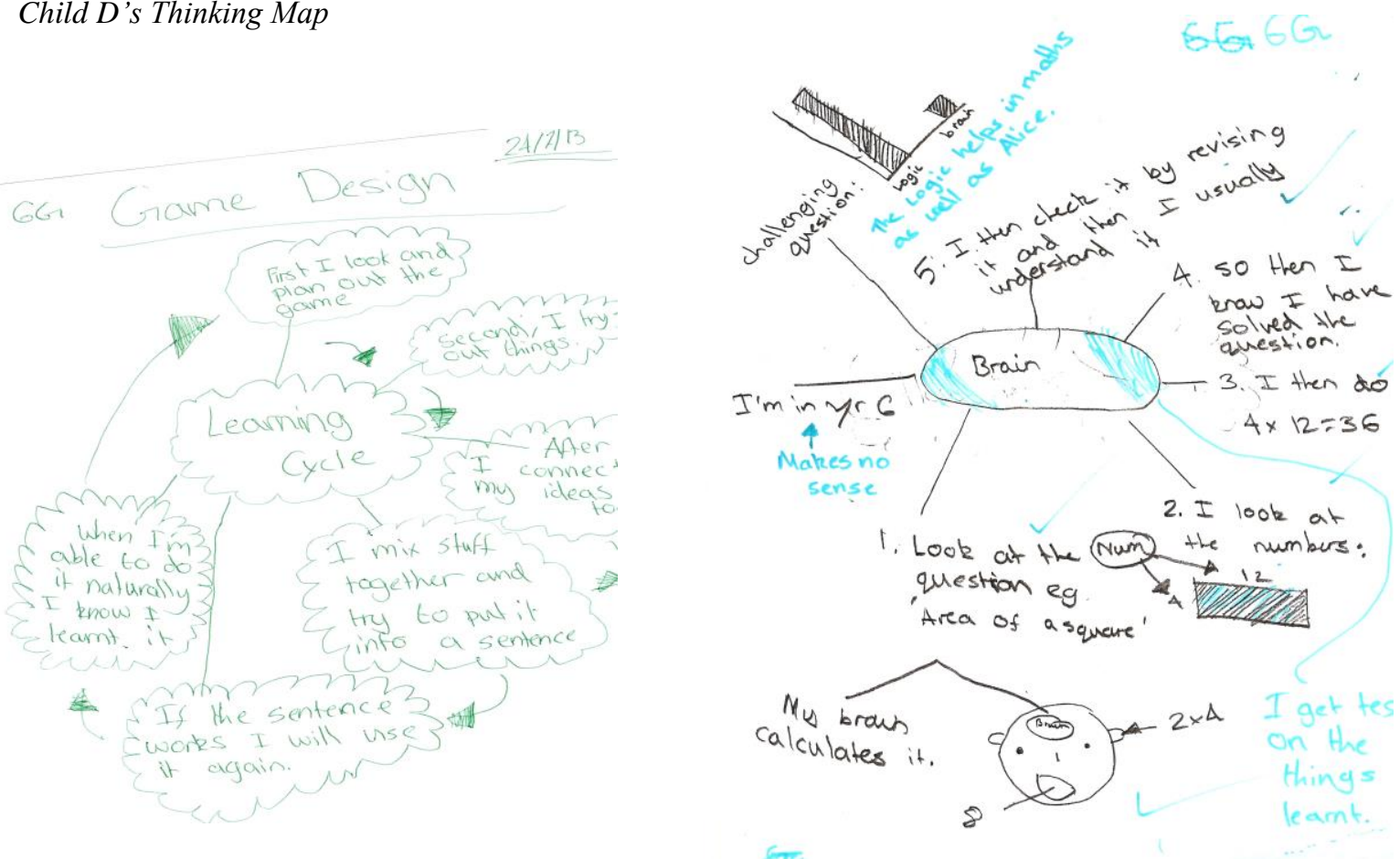

Figure 7: Child D's Pre-project Thinking Map annotations Figure 8: Child D's After-project Thinking Map

In his before game design map, Child D places the brain at the centre of his diagram. He then has sentences pointing out from the brain in numerical order. He first looks at the question (area of a square given as an example). He looks at the numbers. Then he calculates it. If he got the correct answer, he knows that he has solved the problem. He then revises it to make sure that he understands it. He added 'The logic helps in math as well as Alice' to his map during game design. When he was asked to explain this; his answer was "Well, it is really logic isn't it, if you can understand things, like connecting what you know and make sense of things, then you can solve any problem, could be in maths, like algebra, or in Alice like you want the space man to fly. You can do it if you can understand it, then you kind of know it."

His after game design thinking map had a different layout. He placed 'Learning cycle' word at the centre, his mental activities were situated around these words and linked via arrows which shows a type of continual cycle. He suggested that he first look and plan out the game (Engage/Engineer), then he try out things (Explore), this is followed by connecting his ideas, mixing stuff and putting into a 


\section{A study into children's cognition when making computer games}

sentence (coding- Experiment), if the sentence works, he uses again, when he can do this (coding) naturally he describes this as learning

Child D's thinking process starts with engineering ideas, and he then moves onto explore and experimenting. Once he is sure that his coding can make his idea happen, he uses this to design his game (Elicit).

\section{A conversation with children on thinking and game design}

Although it is not possible to share all of the points made by the children here, there were some comments definitely worthy of a mention. The children thought that they had to do more when designing computer games because there wasn't always someone sitting next to them to help them. One child expressed this as, 'I think you have to link ideas because there isn't always a teacher besides you all the time, and not everybody knows game design. Teachers know maths and literacy because they learned to do that, I think you have to link ideas and think outside the box because you don't always have help'.

Many of them compared game design with learning a new language. One child said, "Maths, English is the language we understand. We know what $5+5$ means. In Alice at the beginning we don't understand what it means, then we learn to do things. If you want something to move without you controlling it, you don't know because it is a different language. It is a coding language. You have to think deeper ". They also discussed how as they learn to understand this language, they used similar codes to program the objects to do different actions. "But you don't need to learn each movement as a different sentence. You could use the same coding for different actions. It could be like just adding stuff. When you're swimming you could just do move forward then move up or out, so you don't create all different, you need to add one more. Basically you need to know if you can use previous coding for another stuff'.

When they were asked about the 'Thinking sequence' during game design, they had a wide range of mental activities involved. However 'imagining, visualizing' were the most mentioned words. Some of their comments were:

"I think about the motion in real life. When I think about swimming, I think about like I move my arms up and down'.

"When you do maths, lets say a word problem, the answer is usually in the question. But in Alice you have to start from beginning and make an imaginary world and you have to make something to solve the problem".

“Sometimes you visualize it'.

"I imagine the game before I make it. If I make a game where it is a car game, in a city, first I make the scene-imagine the city, then the car and I think about what to do with it".

They also mentioned the word 'lab' quiet often. They talked about the virtual lab (lab in mind) and physical lab (the program) and how they connect them through design in mind then test on screen.

"You turn the program into a lab, because you try out things on it. When you press 'play', you are basically testing, it is a real-physical lab really”.

"I use my mind lab, my virtual lab to match it with realistic lab. I plan it in my virtual one then test it using the program”.

"I test it out in my mind. If it is not realistic, then I won't try on my design, because I know it won't work".

"I try to design the movements in my mind but I try out on the program, because the codes are on the program, not all in my mind”.

"I kind of visualize it in my mind. It is like pressing the 'play' button, but making it as you go. Like I need to make the man move forward, so that the other one can talk. You go to the real program to 
make it real".

One interesting point came out when they discussed the link between thinking and learning. One child described the process using another scientific example; "It is like electricity and a light switch. They need each other to turn on the light. With only electricity you couldn't do something, you need the switch to turn on the light". When another child asked; How do you apply this to game design? Her reply was; "Switch is learning, electricity is thinking as it keeps going, never stops". Then another child asked; "What is the light bulb then?" Her answer was; "The light bulb is the end result, the solution, like your game design'.

\section{Defining a Model for Think-to-learn-to-think cycle, $6 \mathrm{E}$ Model}

Although this was a small study as part of larger research with a specific focus, it provides us with some interesting insights into children's thinking for learning processes during game design activities. The study will continue into the coming years, where the concept will be developed in further depth. At this stage it is still very beneficial to share the main cognitive activities the children reported to accomplish when making their own digital games so far. The study of children's Pre-during-after project Thinking Maps and the explanations they shared during group discussions suggests that their thinking sequences were altered in the during and after game design activities. Some of the changes noticed were:

- Their drawings which represent their thinking processes had a clear layout with a continuous cycle

- Visualising, imagining the solution before testing on screen was included as a main mental activity

- Turning brain into a 'lab'. Many children talked about using their mind as a virtual lab to plan and test their design.

- Talking to 'self'. There were quite a few children that mentioned having a conversation with themselves through thinking in their mind when planning their game or a solution to a problem.

- Naming 'Thinking Map' as 'Learning Cycle'. Although drawing a 'Thinking Map' to show their thinking process was discussed at the beginning, many children labeled their map as a 'Learning cycle'.

The thinking sequence that the children drew when making digital games had a similar pattern. The most frequently mentioned functions were; motivation, exploring (Alice, design ideas), testing (ideasdesign), checking for error and decision making (deciding a game idea, deciding which code to use). What was noticeable was how the majority of the children drew their thinking process as a circular continuous cycle which had the flexibility to allow them to move in between different steps as they needed. The main stages for think-to-learn-to-think cycle can be suggested as; engage, explore, engineer, experiment, elicit and error check/evaluate.

\section{Engage}

Engagement is the core trigger for thinking. Without it, the process of thinking cannot come forth. In every step of the thinking sequence, from creativity to decision making, children need to retain their attention to proceed to the next stage. Their engagement with the activity sometimes alone, sometimes collaboratively with their peers or in partnership with their teacher is the key element for laying the foundations for the thinking process. Although engagement seems to be the starting point for thinking, it is a continual motion, connected to each and every one of the arrays of the thinking system. During the 6 months of the project, the majority of the children were completely engaged with the tasks, some longer than others. There were, however, a few students who from time to time became disconnected from the task. One reason for this could be a lack of cognitive resources to cope with the complex problems. There are some strategies that teachers could use to support learners. They could encourage peer or whole class discussions to identify the main areas that children are having problems with and allow the group to design solutions collaboratively. They could also use questioning to encourage the learners to think aloud and deeper to check out if there is an error in their design. 


\section{A study into children's cognition when making computer games}

\section{Explore}

Once the child has engaged with the activity, they then start to explore the interface of the medium used which they then extend it through exploring ideas and possibilities. When I first introduced the 'Alice' game design program to the children, they spent around 30 minutes randomly clicking on the character and object files, methods, functions, and events. They then looked at the videos available on the Alice website and on You Tube. Before even understanding how the program functions, they had a conversation with their friends on possible narrations for their games. Some of them also tried to copy the tutorials to find out more about what they could do. So it can be said that exploring occurs in two motions; learning about the mechanics of the medium (interface) and knowing what they could manifest with it (narrative).

\section{Engineer}

After exploring the interface of the game design program and the possibilities that they could manifest with it, the children start to engineer their own design ideas. During the 'Alice' project, the way they did this was very individual. Some of them planned their game ideas on paper using a storyboard; some just discussed it with their partner and then directly started to design. There were a few that walked around the classroom to see what others were working on. It was notable that during this stage the interaction between the learners in the classroom was minimal. Their focus and communication was more internalised than social. There were also some discussions around whether it is technically possible to turn their ideas into a design and how they could know this.

\section{Experiment}

This is the stage where testing, trying out takes place. The children check if their idea/s can be manifested into a design. They connect their ideas to the design through constant dialogue through thinking (dialogue with 'self' and 'others') and an action (dialogue with design) before turning these into reality using software. The children had many ideas some of which they could turn into a design but some they couldn't. This doesn't mean that it wasn't possible; they just were not able to design a solution, so they moved onto another idea. For example, one child wanted to have a multi-player car racing game. He managed to be able to have the cars controlled one at a time, but he couldn't find a way to have them controlled by different players using different computers, so he decided to explore ways of having the cars controlled by two players using the same computer. This is quite a fascinating action as it allows children to re-think their problems and design workable solutions. What a life skill to have.

\section{Elicit}

This can be seen as the decision making part of the thinking process. After testing out their idea/s and possibilities the children select the one/s that they like, which then they work on to develop into a game. In our project this stage was the longest one. It is also firmly linked to the experiment stage. This project made the children understand the importance of making the correct choice and deciding carefully. Every time they made the wrong choice they had to experiment with different idea/s. Their issues with the decision-making stage became more visible towards the end of the project, where some were very close to completing a game, some still trying out other ideas. In a way, it made them aware of how wrong decisions impact not only on the outcome but also causes time management issues.

\section{Error check/Evaluate}

When designing their games, the children often used the trial method to code. They constantly checked for errors but also evaluated to see if their coding was correct for the action they wanted to create. They reported that they automatically started to check if their design was correct, without even having a problem. They also stated that it is easier to realize your mistake when you are making a game without anyone telling you, because the game will not work. They compared this with a maths lesson when they said, "Until your teacher tells you don't really know you have made a mistake! It is not always easy to see”. 


\section{A study into children's cognition when making computer games}

\section{Conclusion}

The study into children's thinking for learning processes gives us information about the mental activities that the learners performed. What is significant is that, although most of the children's thinking processes followed a similar sequential pattern, the order of steps varied a number of times. This might be related to cognitive resources and previous experiences that the child had prior to the activity.

Another interesting point was their view on how game design impacted on their minds. They talked about using their mind as a lab to plan, visualizing solutions, testing ideas on the screen, checking for errors constantly, and thinking deeper as help was not always available. They suggested that their brain was more active during game design activities as they had to do the most of the work without much support. They described this as; 'thinking deeper' and 'thinking faster' which might be seen as extended cognition. Remembering the focus question at the beginning; Do digital game design activities impact on children's thinking pattern for learning and how? It is clear that there is a firm link between game design activities and the way the child thinks. It can be suggested that whilst making games, children transform their mind into a lab where they can develop and test their designs, through thinking (dialogue with 'self' and 'others') and an action (dialogue with design) before turning these into reality using software. This is a continual and constant 'making sense' process, where children can exercise their planning, decision-making, organizing, testing and evaluating skills; which are a foundation to learning in many areas. The core of this process revolves around the teacher, learning space / task and the student's ability to regulate their own learning through ongoing monitoring and evaluating (metacognition).

This study provides us with a starting point to understand children's thinking process when designing their own games and will continue in the coming years to explore the context of their thinking further when making computer games.

\section{Acknowledgments}

\section{Ethics}

A letter had been prepared by the school office and sent to parents regarding the use of children's photos, videos and work for this study for improving standards in school, that the outcome of the research would be published online and/or in a written publication. All of the children's parents signed these letters.

Working with such young children as part of this study, understanding the ethical principals for conducting this research was extremely important. BERA guidelines (2011) were followed for this purpose. The purpose of the study was explained to the participants so that they were aware of the aims of the research project. They were also informed that their participation was voluntary and that they may withdraw from the study any time. They were also given information about the research procedure so that they knew what to expect in the study.

The data (video transcripts, children's game designs, thinking maps) can be shared at request providing no data physically will be downloaded and used in any other research.

\section{Conflict of Interest}

I have no conflicts of interest to declare in relation to this study.

\section{References}

BERA (2011). Ethical Guidelines for Educational Research. British Educational Research Association. Retrived online 12 June 2014 at: http://www.bera.ac.uk/system/files/BERA\%20Ethical\%20Guidelines\%202011_0.pdf

Bransford, J. D., Brown, A. L., \& Cocking, R. R. (Eds.). (2000). Learning and transfer (Chapter 3). In How people learn: Brain, mind, experience, and school (pp. 51-78). Washington, DC: National Academy Press.

Buckingham, David \& Burn, Andrew (2007): Game Literacy in Theory and Practice. Journal of Educational Multimedia and Hypermedia, 16(3), 323-349.

Cross, D. R. \& Paris, S. G. (1988). Developmental and instructional analyses of children's metacognition and reading comprehension. Journal of Educational Psychology, 80(2), 131-142. 


\section{A study into children's cognition when making computer games}

DfES (2004) National Curriculum Thinking Skills. Retrieved online May 23, 2013 at: http://www.bucksict.org.uk/KeyStage3/CourseMaterials/IncreasingProgress/Resources\%20for\%20sess ion\%201/ho\%201.5.pdf

Dyer, G. (2008). Making Digital Games . . an exploration of game authoring in primary schools. Retrieved online June 12, 2013 at:

https://www.det.nsw.edu.au/media/downloads/detawscholar/scholarships/yr08/june/gdyer.doc Fisher R. (1998), Thinking about Thinking: developing metacognition in children. Early Child Development and Care, Vol 141 (1998) pp1-15. Retrieved online June 12, 2013 at:

http://www.teachingthinking.net/thinking/web\%20resources/robert_fisher_thinkingaboutthinking.htm Flavell, J. H. (1979). Metacognition and cognitive monitoring: A new area of cognitive-developmental inquiry. American Psychologist, 34, 906-911.

Jessel, J. (2012). Social, cultural and cognitive processes and new technologies in education in Miglino, O., Nigrelli, M. L., \& Sica, L. S. Role-games, computer simulations, robots and augmented reality as new learning technologies: A guide for teacher educators and trainers Napoli: Liguori Editore

Jonassen, D., \& Reeves, T. (1996). Learning with technology: Using computers as cognitive tools. In D. H. Jonassen (Ed.), Handbook of research in educational communications and technology (pp. 693719). New York: Simon \& Schuster Macmillan.

Jonassen, D. (1999). Designing constructivist learning environments. In C. Reigeluth (Ed.), Instructional design theories and models: A new paradigm of instructional theory (Vol. II, pp. 215239). Mahwah, NJ: Lawrence Erlbaum Associates

Kafai, Y. B., \& Resnick, M. (Eds.). (1996). Constructionism in practice: Designing, Thinking, and Learning in a Digital World. Mahwah, NJ: Lawrence Erlbaum

Kafai, Y. B. (1995). Minds in play: Computer game design as a context for children's learning. Mahwah, NJ: Lawrence Erlbaum

Papert, S (1998). Does Easy do it? Children,Games, and Learning . Retrieved online 25 June, 2013 at: http://www.papert.org/articles/Doeseasydoit.html

Robertson, J. and Good, J. (2004). Children's narrative development through computer game authoring. In Interaction Design and Children 2004 Conference Proceedings, pp. 57-64, New York: ACM Press.

Sternberg, R.J. (1998, April). Abilities are forms of developing expertise. Educational Researcher, 27 (3), 11-20

Yatim, M.H.M. and Masuch, M. (2007). Educating Children through Game Making Activity. Paper presented at Game in' Action, Göteborg University, Sweden 